\title{
Revolución cultural y el choque de paradigmas ${ }^{1}$
}

https://doi.org/10.21830/9789585287884.03

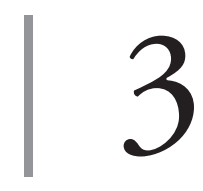

Dario Enrique Cortés Castillo ${ }^{2}$

Escuela Superior de Guerra "General Rafael Reyes Prieto"

Paola Alexandra Sierra-Zamora ${ }^{3}$

Escuela de Aviación del Ejército

\section{Resumen}

Superada la Guerra Fría como contienda de confrontación ideológica entre capitalismo y comunismo, y expuesta la tesis de Fukuyama del fin de la historia, la humanidad incursionó en un nuevo orden, u orden emergente, caracterizado por la prevalencia de una potencia que se proclamó hegemónica, la globalización, las políticas de austeridad y el libre mercado tutelados por el Consenso de Washington. Este escenario propició que los países y vertientes antagónicas al modelo capitalista neoliberal, particularmente en América Latina, plantearan la posibilidad de un cambio de época. De esta manera, inspirado en las tesis del marxismo crítico y guiado por el pensamiento de Antonio Gramsci, el marxismo latinoamericano se reestructuró y, con base en la tesis emancipadora, validó la vigencia del marxismo como estrategia para enfrentar el paradigma capitalista mediante la revolución cultural. Con el objetivo de contribuir a la comprensión de la polarización ideológica regional, en este capítulo se presenta un análisis del discurso cualitativo y descriptivo sobre los fundamentos que sustentan la idea de que el capitalismo es una teoría inhumana, los errores del marxismo leninismo y las tesis del marxismo humanista

1 Este capítulo forma parte de los resultados del proyecto de investigación "Estrategia nacional: por una Política de Seguridad y Defensa a la vanguardia de las amenazas contemporáneas", del grupo de investigación Masa Crítica, de la Escuela Superior de Guerra "General Rafael Reyes Prieto", registrado con el código COL0123247 y categorizado en B por Minciencias. Los puntos de vista pertenecen a los autores y no reflejan necesariamente los de las instituciones participantes.

2 Magíster en Inteligencia Estratégica de la Escuela de Inteligencia y Contrainteligencia "Bg. Ricardo Charry Solano". Magíster en Ciencias Sociales de la Universidad Jaume I, Espańa. Profesional en Ciencias Militares de la Escuela Militar de Cadetes "General José María Córdova”, Bogotá, D. C. ORCID: https://orcid. org/0000-0002-7593-1673. Contacto: dario.cortes@esdegue.edu.co.

3 Abogada de la Universidad Católica de Colombia. Magíster en Derechos Humanos, Democracia y Justicia Internacional de la Universitat de València, España. Doctorado (en curso) del Programa de Derechos Humanos, Democracia y Justicia Internacional de la Universitat de València, España. Investigadora de la Escuela de Aviación del Ejército, Bogotá, D. C., Colombia. ORCID: https:/orcid.org/0000-0002-3146-7418. Contacto: paolasierrazamora@cedoc.edu.co 
que permitan refrendar la vigencia del pensamiento del marxismo humanista o crítico como nuevo paradigma que enfrenta al capitalismo neoliberal.

Palabras clave: capitalismo neoliberal; desde abajo; marxismo humanista; paradigma; revolución cultural.

\section{Introducción}

Finalizada la Guerra Fría y expuestas las directrices económicas y políticas del nuevo orden mundial, caracterizado por la adopción del capitalismo neoliberal como modelo económico e ideología política dominante (De Sousa, 2014, p. 163), la definición de la democracia como sistema de gobierno y la declaratoria de unipolaridad por parte de los Estados Unidos de Norteamérica como actor supremo del tablero geopolítico motivaron a otras potencias y vertientes de pensamiento antagónicas al modelo unipolar y de capitalismo neoliberal a disputar esta supremacía en el gran tablero mundial (Brzezinski, 1997). De acuerdo con Borón y Massholder (2014), "los Estados Unidos eran percibidos, en sentido amplio, como una representación del futuro, como una sociedad digna de admiración y que merecía ser emulada” (p. 40).

En este contexto, diversos sectores de la intelectualidad progresista latinoamericana plantearon la necesidad de estructurar alternativas contrahegemónicas, altermundistas y de liberación. Para esto partieron de la crítica al modelo de desarrollo dominante impuesto por el neoliberalismo (Escobar, 2014) y la autocrítica del socialismo real (Harnecker, 1999), además auscultaron la teoría ante las circunstancias concretas del momento histórico y desde el neomarxismo para enfrentar el modelo imperante y superar las falencias del marxismo-leninismo. De esta manera, reeditando el marxismo, buscan impulsar un proceso civilizatorio que articule la multiplicidad de cosmovisiones que conduzcan a emancipar la humanidad.

Lo que está bajo crítica no son solamente las políticas de los gobiernos neoliberales, o la relación de dependencia de la periferia, o el sistema capitalista, sino el sistema civilizatorio de la modernidad eurocéntrica, que en el siglo XX se constituyó como proyecto desarrollista. (Coraggio, 2014, p. 168)

Por lo expuesto, el presente escrito pretende de forma cualitativa y descriptiva, mediante el análisis del discurso, abordar a manera de hipótesis: ¡el marxismo humanista desde la teoría de la filosofía de la praxis y la revolución cultural como estrategia general se constituye en el nuevo paradigma que enfrente al capitalismo neoliberal? 


\section{Caracterización del capitalismo neoliberal}

Declarado el fin de la historia ante el fracaso de la utopía comunista, emerge para la humanidad un nuevo orden global interconectado y solidario en el que de la potencia hegemónica emanan las directrices político, económicas, culturales y militares (Fair, 2008a) que definen la democracia liberal como la forma de gobierno que debe ser extendida por el mundo y al neoliberalismo como el modelo económico y de desarrollo que se debe aplicar en todo el planeta. De esta manera, el proyecto de capitalismo democrático da fiel cumplimiento a la concepción de que "no podría haber democracia sin capitalismo, ya que los dos eran considerados intrínsecamente inseparables" (Fair, 2008b).

La propuesta del modelo de desarrollo de plena libertad de los mercados que vislumbra los desafíos de crecimiento, equidad, sustentabilidad y gobernabilidad (Munck, 2017, p. 57) — considera que para alcanzar el progreso es necesario aplicar las tesis del libre mercado, libre cambio, movilidad de capitales, bienes y servicios, desregularización del mercado, reducción del Estado y el protagonismo de los organismos multilaterales (Banco Mundial, Fondo Monetario Internacional [FMI], etc.), las corporaciones multinacionales y los grupos empresariales. De esta manera, se pretendió garantizar el crecimiento económico en beneficio del bienestar común y la prosperidad de la humanidad (Palacios, 1998, p. 67) desde una versión del neoliberalismo renovado:

El modelo neoliberal permitiría a sus países "insertarse en el mundo", acceder al crecimiento de sus economías y, mediante un efecto "derrame" basado en la "mano invisible" del mercado, generar un "desarrollo sustentable" que se distribuiría a todos los habitantes del planeta. (Fair, 2008a, p. 4)

Sin embargo, la práctica neoliberal ha recibido críticas desde diversas vertientes del pensamiento moderado y crítico, que llaman la atención sobre su teoría e incluso llegan a equipararla con el marxismo eurocéntrico, debido a las pretensiones que tiene de imponer sus postulados políticos y económicos a todos los países del mundo. Al respecto, el filósofo John Gray (2002) señala que "los neoliberales son deterministas económicos, igual que los marxistas. Creen que todos los países están destinados a adoptar el mismo sistema económico y, por ende, las mismas instituciones políticas" (2002, p. 1).

Precisamente, las teorías críticas han cuestionado los fundamentos que sustentan el modelo neoliberal con base en el análisis de sus diversas variables y evolución. Entre estas teorías se pueden mencionar la de la dependencia, el neoestructuralismo, el posestructuralismo, el posmodernismo y el posdesarrollo, las 
cuales se complementan con el aporte de autores de variadas disciplinas, como Immanuel Wallerstein, Franz J. Hinkelammert (2005), Gilbert Rist, Hardt, Negri, Foucault, Samir Amín, Atilio Borón (2006), Enrique Dussel, Leonardo Boff, Raúl Fornet-Betancourt, Gustavo Gutiérrez, Humberto Márquez, Manuel Castells, Ana Esther Ceceña, Armando Bartra (2013) y Arturo Escobar, entre otros. De manera concordante y complementaria, estos pensadores califican el capitalismo neoliberal como un modelo en crisis que por su carácter y multidimensionalidad promueve ajustes estructurales que conducen a las sociedades al endeudamiento, la miseria, la inestabilidad laboral, la hambruna y la depredación, de tal manera que tiene sentido plantear una crítica al modelo de abundancia prometido. Específicamente, los autores exponen que el modelo de desarrollo promovido por el capitalismo conlleva una crisis civilizatoria, en el sentido que es percibida como una compleja crisis "con rostro multidimensional que expone los límites de la valorización mundial de capital por cuanto atenta en contra de los fundamentos de la riqueza: el ser humano y la naturaleza, y porque pone en predicamento el sistema de vida en la Tierra, es decir, el metabolismo social” (Márquez, 2009, p. 193).

Desde el estallido bancario de 2008 han aparecido muchos signos de una crisis sistémica del capitalismo. Esta convulsión no expresa solo el agotamiento de un régimen de acumulación o el estallido de la financiarización. Ha salido a flote una crisis múltiple de gran alcance social, geopolítico y ambiental. (Katz, 2010, p. 5)

En realidad se trata de la confluencia de múltiples crisis — "estructural, hegemónica, institucional, política y sistémica” (Márquez, 2010, p. 66) — que superan de lejos la mera calificación de crisis capitalista. Por lo tanto, se puede colegir que no se trata solo del capitalismo, sino también de la humanidad, pues es arrastrada simultáneamente por graves problemáticas alimentarias, climáticas, ecológicas y energéticas (Vega, 2009), de manera que las desigualdades sociales se profundizan y se pone en riesgo la vida de gran parte de los habitantes y formas de vida del planeta.

En su comprensión más gruesa, la crisis es percibida como civilizatoria: estructural, institucional, política, hegemónica y sistémica, en suma, una crisis de la humanidad. La emergencia de una multiplicidad de crisis, como la alimentaria, energética o laboral, que profundizan las desigualdades sociales y ponen en riesgo la vida de gran parte de los habitantes del planeta, [...] por lo mismo se habla de una crisis en el modelo civilizatorio. (Márquez, 2010, p. 66)

De acuerdo con la teoría crítica, el modelo transita las circunstancias contradictorias que describen las tesis de nivelación e igualdad de los mercados que expusieron con optimismo Adam Smith y David Ricardo. Sin embargo, se advierte 
además que tiene el agravante de que en su práctica moderna articula "la vertiginosa mundialización de los flujos financieros” con la cobertura geográfica global y la uniformización cultural (Borón, 1999, p. 140). Desde esta perspectiva, dicha articulación no solo no propicia la integración anhelada, sino que además ocasiona un efecto discriminatorio o excluyente debido a que los inversionistas prefieren las zonas más fructíferas sobre las menos lucrativas, lo cual propicia que emerjan fundamentalismos, migraciones y despertares identitarios (Baeza, 2006). Además de estos efectos, los críticos señalan que el modelo de globalización somete a sus contradictores no capitalistas con la creación de un espacio económico universal y la "homogeneización cultural", que, impulsada por los oligopolios mediáticos, impone a manera de alienación valores y estilos culturales que expanden un "modelo de consumo completamente estandarizado, descontextualizado, fetichísticamente igualitario, barato y de baja calidad” (Borón, 1999, p. 142).

Esta creciente homogeneización cultural ha sido un instrumento poderosísimo para la creación de un "sentido común" neoliberal que exalta las oportunidades que ofrece el mercado, lo que tal vez constituye el triunfo más notable de la restructuración regresiva del capitalismo actualmente en curso. (Borón, 1999, p. 6)

En este sentido, el eje central de la discusión plantea que la esencia del modelo neoliberal es alienante, pues supera el ámbito meramente económico y expande los tentáculos de su cosmovisión, un proceso civilizatorio que convierte al consumo en la razón de ser de todo, "en la moda, en la lógica cultural y en el canon de toda la producción estética" (Márquez, 2017, p. 135). De esta forma, "la actividad humana principal sería la económica y esta se realizaría en el mercado", por lo cual las "funciones humanas esenciales" desde la perspectiva de pensamiento único serán las de "poseer, intercambiar, acumular y consumir" (Vergara, 2003, p. 6).

En perspectiva, esta nueva cosmovisión refrenda una sola representación de la vida y del pensamiento único, configura las verdades y los valores. Asimismo, elabora dogmas económicos, políticos y sociales que son reproducidos en los países del mundo por los medios masivos de comunicación. De esta manera, se constituyen en credos uniformizantes que, con las tesis del libre mercado, guían las prácticas y los comportamientos colectivos de una nueva sociedad (Silva, 2017) que, alienada, atenta contra las múltiples culturas.

La cara uniformizante, eurocéntrica, aplastadora y asesina, que da validez a una sola forma de concebir la vida, una sola forma de pensamiento, una sola civilización y un solo modo de producción: la capitalista. Es la cara que ha dado origen a las terribles guerras del siglo XX, al exterminio de múltiples culturas. (Lang, 2013, p. 20) 
Así, con la intención de alcanzar las metas de crecimiento, equidad, sustentabilidad y gobernabilidad, el neoliberalismo establece un nuevo orden moral y ético que justifica sus acciones con valores de orden económico. Por ejemplo, se considera que el consumismo y la competitividad son un instrumento para alcanzar el mayor beneficio económico, de cualquier forma y por cualquier medio. Otros valores son el individualismo, que destaca la capacidad, los méritos y los logros personales en contraposición al bien común; la mercantilización de todos los aspectos y facetas de la vida humana, que fomenta la iniciativa privada y los nuevos nichos de mercado, para lo cual expande su práctica a Derechos Humanos más básicos y fundamentales, los convierte en mercancías y reduce significativamente el tamaño del Estado; el emprendimiento como corolario del individualismo y la competitividad, que promueve la creación de empresas como fuente de generación de empleo y aumento de la riqueza del país, y, finalmente, la privatización de los servicios públicos y la alergia a los mecanismos de reparto o de redistribución (Silva, 2017).

En el orden social, el neoliberalismo también construye un sistema de valores, entre los cuales se pueden mencionar los siguientes: el culto y la adoración por los ricos y poderosos, a quienes entronizan como referentes y modelos por seguir; el culto a las posesiones materiales; la banalidad de lo superfluo y la frivolidad social, que consiste en un proceso de alienación que desvía la atención de la sociedad hacia aspectos banales; la visión uniforme y excluyente de la sociedad, mediante la cual se satanizan expresiones alternativas al modelo neoliberal; la legitimación de la desigualdad como proceso natural; la corrupción como norma y parte inherente al sistema; el desprecio absoluto a los animales y a la naturaleza, pues se legitima la explotación salvaje de los recursos naturales, el saqueo y la destrucción de la naturaleza; el culto al heteropatriarcado, que relega a la mujer a un segundo plano y que se expresa en el terreno de las desigualdades sociales (género, étnicas, diversidad sexual); y, finalmente, la negación de derechos y la exaltación de otros, como sucede con el derecho a la propiedad privada, que el neoliberalismo sitúa sobre los derechos económicos, sociales, culturales y ambientales (DESCA) (Silva, 2017).

En la práctica, al promover los derechos de la propiedad y el capital sobre los derechos político-civiles y sociales, el capitalismo "favorece la práctica de medidas abusivas que vulneran la dignidad de los seres humanos" (Tejedor, 2014, p. 47), a tal extremo que el trabajador en la era de la globalización ha sido nuevamente categorizado como un objeto que ante las necesidades de subsistencia se vende al mejor postor, con lo cual pierde su esencia como ser humano (Castellanos \& Suárez, 2009, p. 388). 
En el capitalismo se concibe que el bienestar se logra con un consumo ilimitado que satisface necesidades individualistas. Estas, inducidas por la economía, se convierten en necesidades alienadas que vuelven funcionales la vida humana y las relaciones sociales a las prioridades de la producción, cuyos patrones se han vuelto insostenibles. (Herreño, 2009, p. 241)

Es decir, el neoliberalismo convierte a los Derechos Humanos en antagonistas de las pretensiones de acumulación del modelo de desarrollo. De acuerdo con Patiño (2004), "estos Derechos Humanos parecen incompatibles con una globalización neoliberal inhumana y excluyente de los beneficios del desarrollo” (p. 3).

En este contexto, el modelo hegemónico, por intermedio de los intelectuales y los medios masivos de comunicación, convierte en filosofía popular las ilusiones y expectativas del mercado (Vergara, 2003). Para conseguirlo, crea una "ilusión de consenso" (Fair, 2010) en la sociedad, sobre la cual cimenta su discurso ideológico que transforma el sentido común con su concepción del mercado para garantizar "la maximización de la producción en conexión con el sistema de valores de la sociedad" (Baudrillar, 2009, p. 69). De ahí que los valores inspirados en el aumento de la libertad individual como libertad del mercado, en aras de alcanzar la máxima productividad y rentabilidad del capitalismo neoliberal, impulsan la transgresión de los límites del interés general y dan paso a las prácticas destructivas y excluyentes, de cuyas consecuencias no se hacen responsables (Vergara, 2003). De acuerdo con Hinkelammert (2001) y Vergara (2003), la teoría neoliberal

está a la base de la lógica de las decisiones económicas, las cuales se guían exclusivamente por los criterios de eficacia, entendida como la maximización de la rentabilidad (Hinkelammert, 2001, p. 15). Esta es una lógica de racionalidad fragmentaria, incapaz de percibir los efectos indeseables y destructivos de sus acciones. En su intento de realizar el mercado total, es incapaz de comprender los límites ambientales de crecimiento económico, así como los límites sociales y psicosociales. (Vergara, 2003, p. 15)

Los efectos que tiene transgredir los límites de la libertad individual incluyen mayores niveles de contaminación, el saqueo del subsuelo, la desertificación, la extinción de las selvas y la desaparición de los bosques, que se traducen en la depredación del medio ambiente (Katz, 2014) como consecuencia del extractivismo depredador y los monocultivos (Gudynas, 2013).

En este panorama caótico que produce el consumismo se puede colegir que el modelo no solo ha incumplido sus tesis de bienestar para la humanidad, sino que además ha fomentado la explotación del hombre por el hombre y del hombre 
contra la naturaleza, lo cual conlleva la destrucción de la humanidad. En pocas palabras, es más que evidente que el modelo tiene un carácter inhumano.

Las advertencias sobre la necesidad de que el desarrollo de la economía no se haga a expensas del derecho de las futuras generaciones a una vida saludable en el planeta (algunos dirán: del derecho de la propia naturaleza, de la propia Tierra), a las críticas a la licuación de los valores de la solidaridad y la integración social en manos de la locura consumista a la que nos lleva el desarrollo de un capitalismo desaprensivo y cada vez más in-humano. (Rinesi, 2014, p. 15)

Finalmente, se debe señalar que la naturaleza humana que engendra el modelo desarrollista produce sujetos egoístas, despiadados y ambiciosos que acuden a métodos extractivistas y modelos de crecimiento a cualquier precio que ponen en riesgo la existencia de la humanidad y las expresiones de vida en el planeta. Precisamente, esta apreciación hace que la crítica del modelo plantee tesis posdesarrollistas, las cuales impugnan las cosmovisiones totalizadoras (Katz, 2014) y proponen un proceso alternativo de desarrollo que cobra relevancia en América. En este escenario, desde América Latina surgen alternativas que se contraponen a la unipolaridad y al capitalismo neoliberal con propuestas que convalidan la vigencia del marxismo.

La crisis ofrece condiciones inmejorables para el cambio estructural y sistémico. América Latina es considerada la región que mayor oposición ha mostrado ante la reestructuración y expansión neoliberal. Es el caso particular de países encabezados por gobiernos de izquierda, como Venezuela, Bolivia, Ecuador y Cuba. En estas experiencias se encarna el llamado Socialismo del siglo XXI, desde el cual se postula que el capitalismo es la fuente de todos los males y en su seno no se encuentra ninguna solución. (Márquez, 2010, p. 79)

\section{La crisis del marxismo-leninismo}

Luego del colapso de la Unión de Repúblicas Socialistas Soviéticas [URSS], que trajo aparejado la caída del muro de Berlín, la reunificación alemana y el fin del Pacto de Varsovia, extensos sectores de la sociedad triunfalista preconizaron el ocaso del marxismo, sin percatarse o advertir que lo sucedido solo implicaba una de las vertientes del marxismo, en particular del marxismo-leninismo o del socialismo real. Las circunstancias de los acontecimientos que vitoreaban el fin de la historia, llamaron la atención de los intelectuales de izquierda, quienes plantearon la discusión sobre el futuro de la utopía. 
Algunos sectores invadidos por el pesimismo y la desventura respondieron a los acontecimientos como si se tratara de un cataclismo, de modo que hicieron del panorama teórico y crítico algo más complejo y confuso (Sotelo, 2005). Sin embargo, desde otras visiones más objetivas, los intelectuales críticos latinoamericanos alentaron el ejercicio de la autocrítica sobre la vertiente responsable de los sucesos. De esta manera, los estudios orientados por la síntesis práxica analizaron los fundamentos teóricos del marxismo y su praxis desde el modelo estalinista, así como su incidencia en la dirección de los procesos revolucionarios de América Latina. Por esta vía, también abordaron las particularidades del proceso que articula el modelo del centralismo democrático, la dictadura del proletariado, la dirección de la vanguardia del partido único, el modelo de economía centralizada, la democracia como eje central del socialismo y la propiedad social de los medios de producción, con lo cual buscaban identificar las contradicciones que propiciaron el fracaso de la vertiente del socialismo real.

En este sentido, estos análisis evidenciaron que el vanguardismo del Partido Comunista de la Unión Soviética (PCUS) se transformó progresivamente en una de sus contradicciones, pues se convirtió en una élite revolucionaria burocratizada que se arrogó las funciones de guardia de la revolución. Además, se distanció de su compromiso de tutelar la línea política del partido, la línea de principios y la unidad entre teoría y práctica, mientras se inclinaba por las prácticas de terror de control social.

El aparato político de Stalin suprimió activamente las prácticas revolucionarias de masas en la misma Rusia, y las desalentó o las saboteó de manera creciente fuera de la Unión Soviética. La consolidación de un estrato burocrático privilegiado, por encima de la clase obrera, quedó asegurada por un régimen policial de creciente ferocidad. En estas condiciones, se destruyó ineluctablemente la unidad revolucionaria entre teoría y práctica que había hecho posible el bolchevismo clásico. (Lince, 2017, p. 343)

Otra de las contradicciones estaba en la dirección colegiada del partido asignada al Comité Central. Específicamente, el régimen ejercía un gobierno monolítico basado en el culto a la personalidad, sobre el cual se maquillaban las más graves perversiones a los "principios del partido, de la democracia del partido, de la legalidad revolucionaria” (Kruschev, 1956, p. 1). En consecuencia, la conducción política del partido — anquilosada y aburguesada— perdió interés en conservar

4 Entendida como "la lectura filosófica del decurso del movimiento para sacar lecciones, aprendizajes e incidir conscientemente en el movimiento, saber ponderar el legado, el acervo, los pasos andados con errores y aciertos" (Lince, 2017, p. 338). 
y avivar la esencia revolucionaria que reside en el gobierno del pueblo y para el pueblo. Escudada en el precepto de que "el partido nunca se equivoca", desconoció de manera autoritaria las realidades objetivas y trabajó para intereses diferentes a los de clase, lo cual ocasionó el distanciamiento del pueblo (Valenzuela, 2006).

En este contexto, la realidad también empieza a mostrar que el ideal comunista se va alejando más y más, que se torna nebuloso y, ya para algunos, imposible. Con lo cual, la posible "fuerza moral" que antes pudo morar en el grupo burocrático de dirección ("trabajamos por el comunismo"), se derrumba del todo. (Valenzuela, 2006, p. 139)

A estos errores se sumó la persecución sistemática de las vertientes de pensamiento que discrepaban del pensamiento único. Con el concepto del "enemigo del pueblo", Stalin justificó la eliminación, la deportación y la persecución despiadada de trotskistas, zinovievistas, bujarinistas, comunistas honrados y dirigentes del partido que no comulgaban con sus prácticas, de manera que negó toda posibilidad de alimentar la discusión teórica revolucionaria, al tiempo que violaba las normas de legalidad revolucionaria.

Este concepto de "enemigo del pueblo", finalmente, eliminó todas las posibilidades de que se desarrollaran luchas ideológicas o de que alguien pudiese dar a conocer su punto de vista respecto a cualquier problema, aunque ellos fuesen meramente de carácter práctico. (Kruschev, 1956, p. 1)

El modelo de economía planificada también produjo grandes decepciones. Los planteamientos sobre la propiedad estatal de los medios de producción, la planificación económica y los mecanismos de coerción a manera de dictadura económica de "explotación militar feudal" impulsaron la colectivización del agro. Si bien esto fortaleció el sector mercantilizado de la producción, también ocasionó la liquidación de la pequeña producción y la extensión de la hambruna, con las consecuencias sobre la dignidad y la vida de millones de campesinos y la relación obrero-campesino (Valenzuela, 2006).

La propiedad social de los medios de producción no es un fin en sí mismo, es el único medio de que la economía sea gestionada democráticamente. No puede gestionarse lo que no se posee. El pueblo debe poseer los medios de producción, por lo menos los principales, para poder gestionarlos democráticamente. (López, 2014, p. 1)

Dentro del modelo de capitalismo de Estado, las discrepancias con los postulados fundacionales del marxismo se profundizan con el modelo de producción 
industrial caracterizado por la jerarquización, el autoritarismo y la explotación del obrero, que luego de largas jornadas de trabajo recibe exiguas remuneraciones. De esta manera, el sistema que promulgaba la lucha contra la explotación del hombre por el hombre caía en una práctica enajenante del ser humano.

En la URSS y las restantes sociedades "no-capitalistas" que pasaron por la deriva burocrático-estalinista, las expropiaciones y la estatización de las palancas fundamentales de la economía eliminaron la dominación de los antiguos propietarios privados, pero se mantuvo bajo una nueva forma el heredado antagonismo expresado en la relación-capital y por tanto el trabajo siguió sometido al comando de una voluntad ajena, personificada ahora en la casta burocrática. (Casas, 2007, p. 1)

Finalmente, cabe señalar que al comunismo internacional sujeto a las tesis del marxismo-leninismo le correspondió vivir las deformaciones que surgieron de las utopías y las contradicciones elaboradas por Stalin y el Partido Comunista de la Unión Soviética (Guerrero, López \& Herrera, 2017).

A partir de esta reflexión, a manera de fiel copia acrítica, los postulados de la práctica revolucionaria bolchevique fueron trasladados a América Latina por sus homólogos de los partidos comunistas. La imposición del proceso bolchevique como la única estrategia válida capaz de conducir a los pueblos explotados y oprimidos a su emancipación cobró graves réditos. Asimismo, la imposición radical del marxismo-leninismo —a manera de pensamiento único — sobre otras vertientes del marxismo latinoamericano redujo la posibilidad de enriquecer la discusión teórica sobre modelos foráneos que permitiera superar las diferencias (Harnecker, 1999) e identificar las maniobras del capitalismo y establecer de qué formas se debía enfrentar el paradigma capitalista: "La mayor parte de los partidos comunistas nacen influidos por la III Internacional, lo cual tiene nefastas consecuencias por el dogmatismo y sectarismo que la caracterizan en esos años y por el absoluto seguidismo a la política de la URSS" (Harnecker \& Rauber, 1991, p. 16).

La apropiación dogmática del pensamiento de Marx tiene su origen en discusiones teóricas del movimiento comunista internacional a principios del siglo XX, con la constitución, a partir del V Congreso de la Internacional Comunista, de categorías cerradas como "marxismo-leninismo" o "bolchevización" [...] a partir de esto, se construyen una serie de manuales, verdaderos ladrillos de bazofia intelectual que contribuyeron a ensuciar la conciencia del movimiento comunista, envilecerlo y depurarlo de su carácter revolucionario. (Lincopi, 2016, p. 1)

La práctica estricta y estrecha del dogma de la Tercera Internacional o Internacional Comunista, que impuso la insurrección como estrategia para liberar 
a los pueblos oprimidos de América, la designación del sujeto de la revolución en el proletariado y la calificación de la religión como el opio del pueblo —que desconocía las características de los pueblos, los valores y tradiciones de los pueblos ancestrales - produjeron serios atranques y retrocesos del proceso revolucionario latinoamericano.

El marxismo dogmático que esos países exportaban era un desestímulo para un pensamiento original y creador que partiera de nuestra propia realidad latinoamericana y de nuestras tradiciones culturales más auténticas. Solo los movimientos revolucionarios que lograron liberarse de estos esquemas o no caer en ellos fueron los que lograron triunfar. (Harnecker \& Rauber, 1991, p. 25)

En este sentido, los partidos comunistas latinoamericanos, fieles a los preceptos de la Internacional Comunista, enviaron a sus militantes a los centros de formación del Comintern en Moscú. Este mecanismo no solo les permitió formar los cuadros para fortalecer la estructura orgánica del movimiento revolucionario de cada país, sino que además la Tercera Internacional podía garantizar la expansión de los lineamientos elaborados por el estado mayor de la revolución mundial.

Con este propósito se crearon varias escuelas de cuadros, como la Universidad Comunista de los Trabajadores de Oriente (KUTV), la Universidad Comunista de Minorías Étnicas del Occidente (KUNMZ), la Universidad rusa de la Amistad de los Pueblos Patricio Lumumba, la Escuela Internacional Lenin (una de las de mayor reconocimiento), entre otras (Jeifets \& Jeifets, 2016).

Varias organizaciones de otras latitudes que disponían de gran cantidad de militantes de base, sufrían también la escasez de funcionarios de diferente nivel que conocieran de marxismo y de mecanismos de organización partidaria. Obviamente, donde más se notaban estas carencias era en los partidos jóvenes de los países del Oriente y de América Latina, donde las tradiciones del movimiento obrero organizado eran casi inexistentes. (Jeifets \& Jeifets, 2016, p. 134)

La actividad proselitista soviética cumplió estrictamente sus preceptos. Al retornar a sus países de origen, los militantes se constituyeron en fieles réplicas de las tesis del marxismo-leninismo, con lo cual se cerraba el ciclo dogmático que desdeñó las iniciativas autóctonas del marxismo latinoamericano por los radicales dogmas del estalinismo.

Durante los años 60 y 70 la URSS se fijó como objetivo extender su influencia por Asia, África y América Latina formando a sus trabajadores y apoyando su lucha por la independencia. Moscú trataba de divulgar la lengua y cultura rusas, así como los valores comunistas. (Stróganov, 2015, p. 1) 
Respecto a la vanguardia, se debe señalar que esta fue adoptada en América Latina mediante la conducción política exclusiva del partido por el pensamiento único, en cabeza de élites autoelectas que se arrogaban la conducción de las masas y del proletariado. Estas élites desconocieron de manera excluyente la existencia de otras vertientes del pensamiento opuestas al régimen y de sectores sociales sobre los que se reconocen las luchas de resistencia, de tal forma que impidieron "que el pueblo fuera el protagonista y constructor del proceso revolucionario" (Guerrero et al., 2017, p. 3). Por esta razón, el socialismo real fue asociado "al socialismo centralista, burocrático, antidemocrático, que negaba el pluripartidismo y el pluralismo ideológico" (Harnecker \& Rauber, 1991, p. 25).

Homogeneizar al sujeto histórico y revolucionario bajo la categoría "proletario"
delimitaba a los sujetos y actores sociales al sector fabril/industrial, por ende urbano,
excluyendo a todo un universo de clase social predominantemente campesina y
artesanal, lo que significaba una marginalidad política en un contexto atrasado y
mayoritariamente rural. (Guerrero et al., 2017, p. 4)

Ahora bien, en el plano organizativo, la estructura de los movimientos revolucionarios latinoamericanos siguió las tesis del centralismo ortodoxo y la conducción verticalista, en la cual el diálogo fluía de la dirigencia hacia las estructuras subalternas de manera autoritaria, sin la más mínima preocupación por convencer a las clases subalternas. La configuración de la estructura piramidal — regida por el comandante como gestor, orientador y conductor militar — condujo a la dirigencia revolucionaria "al autoritarismo, al tratamiento disciplinario de los conflictos ideológicos, a los intentos de fraccionamiento, a las deserciones y al estancamiento de la organización" (Pozzi \& Pérez, 2011, p. 287).

Por lo que se ve, el socialismo en el Tercer Mundo no ha sido demasiado original: reproducción de modelos foráneos, introducción de una ética laboral puritana, adjudicación de los costos del desarrollo acelerado sobre las espaldas de los obreros y los campesinos por medios coercitivos una vez que ha pasado la fase heroica y redistributiva de los primeros tiempos y satisfacción de ciertas necesidades social-psicológicas en los estratos medios radicalizados. (Mancilla, 1989, p. 225)

En síntesis, se puede colegir que los problemas del socialismo real que incidieron negativamente en los procesos revolucionarios latinoamericanos se reducen al dogmatismo, el teoricismo, el vanguardismo, el verticalismo y el autoritarismo. 


\section{El marxismo humanista, la revolución cultural y el paradigma civilizatorio}

El pensamiento crítico caracteriza el capitalismo neoliberal, con su modelo de desarrollo de acumulación dominante, como una teoría inhumana, y sostiene que el dogmatismo, el vanguardismo, el verticalismo y el autoritarismo son los errores que ha cometido la vertiente estalinista del marxismo. En este escenario, los teóricos posdesarrollistas latinoamericanos se dieron a la tarea de auscultar las teorías marxistas que permitieran superar los errores del socialismo real y enfrentar el modelo de destrucción de la humanidad. Su intención no fue otra que cumplir en la lógica con el legado leninista: "Sin teoría revolucionaria no hay práctica revolucionaria” (Monge, 2013, p. 13).

De esta manera, la vertiente del pensamiento crítico latinoamericano tomó distancia de los dogmas construidos desde la visión economicista y determinista que fundamentaron el socialismo real y recogió las tesis del Marx joven que se encontraban en los manuscritos que resguardaba el Instituto Marx-Engels. Cabe recordar que David Riazanov dio a conocer estos documentos a la humanidad, desafiando al régimen de Stalin y asumiendo las graves consecuencias: destitución del instituto, expulsión del partido, detención y posterior fusilamiento en 1938.

En la obra conocida como los Manuscritos económico-filosóficos de 1844 o Manuscritos de París, publicados en 1932 en el tercer tomo de la MEGA (MarxEngels Gesamtausgabe), grosso modo, el filósofo de Tréveris hace una crítica a $L a$ riqueza de las naciones, de Adam Smith (1776), en la cual señala que la división del trabajo emerge de la propiedad privada y de las relaciones de producción. A partir de este análisis, el Marx joven fundamenta la génesis de la lucha de clases en relación con esta división del trabajo, específicamente en la diferenciación entre los dueños de los medios de producción y los obreros, que tan solo eran dueños del trabajo esclavizado. En palabras de Marx:

Damos por supuestas la propiedad privada, la separación del trabajo, capital y tierra, y la de salario, beneficio del capital y renta de la tierra; admitamos la división del trabajo, la competencia, el concepto de valor de cambio, etc. Con la misma Economía Política, con sus mismas palabras, hemos demostrado que el trabajador queda rebajado a mercancía, a la más miserable de todas las mercancías; que la miseria del obrero está en razón inversa de la potencia y magnitud de su producción; que el resultado necesario de la competencia es la acumulación del capital en pocas manos. (Marx, 1974, p. 54) 
Desde esta perspectiva, en la relación entre la propiedad privada y el trabajo se produce "una inversión que transforma el mundo histórico-social de los hombres en un mundo del dinero y de la mercancía, mundo que presenta al hombre como un poder extrańo y hostil" (Marcuse, 1970, p. 20), de la cual además surgen las relaciones de alienación y enajenación en la que los obreros son separados del objeto de su trabajo, de manera que se ven "forzados a venderse ellos mismos como mercancías" para sobrevivir (Marcuse, 1970, p. 20). De acuerdo con el humanismo radical de Marx, estas circunstancias inspiran la revolución proletaria como "única opción y posibilidad real de liberación y plena realización humana” (Lince, 2017, p. 339).

La tesis expuesta en los manuscritos abrió la discusión sobre una nueva interpretación de la teoría política marxista, que hasta ese momento se erigía como modelo absoluto y que se fundamentaba en la visión economicista y en la lucha de masas del proletariado, la cual debía estar articulada a la dirección política del partido. Por este camino, los manuscritos fueron la base para hacer una crítica a la economía política y a la estrategia que se seguía para alcanzar el socialismo, así como para analizar la evolución que tuvo la teoría desde la base económica hasta otras categorías como la religión, el Estado o la cultura, lo cual develaba el tema humanista como guía central.

Esa dualidad de frentes ha generado obstáculos hermenéuticos relevantes, llevando a unos a postular que este es el verdadero marxismo, ligado a la emancipación humana, distanciado del materialismo dialéctico que, por muy dialéctico que fuera, acababa reduciendo el sujeto a soporte estructural; y a otros a sancionar esa lucha por el hombre, por la esencia humana, como humanista, moralista y premarxista, en definitiva, como práctica política alienada que, paradójicamente, cree luchar contra la alienación. (Bermudo, 2010, p. 2)

La publicación de los manuscritos, el fracaso de las revoluciones proletarias en Europa y la burocratización de la URSS alimentaron la creciente división que se estaba dando entre teoría y práctica política, lo cual distanció las discusiones teóricas que permitirían la recomposición de la unidad. En este escenario, la producción teórica se trasladó del partido, como vanguardia de la revolución, a las instituciones de educación superior, de manera que perdió todo contacto con la realidad del proletariado (Amadeo, 2006).

Es en este contexto económico en el que la teoría marxista produjo un cambio profundo, dando origen a lo que se ha dado en llamar "marxismo occidental". Esta tradición se estructuró a partir de los trabajos de una serie de destacados intelectuales provenientes de las regiones occidentales de Europa: Lukács, Korsch, Gramsci, Benjamin, Marcuse, Horkheimer, Adorno, Della Volpe, Colletti, Lefebvre, Sartre y Althusser. (Amadeo, 2006, p. 55) 
El aporte de los teóricos del marxismo occidental distanciado de la ortodoxia se fundamentó en la interpretación de la dialéctica como la relación específica entre el sujeto y el objeto como fórmula contenida de manera indisoluble en la praxis revolucionaria. Para ellos, las transformaciones son algo más que las leyes inmodificables de la ciencia, son el producto de la relación de los individuos en la praxis, que empíricamente producen la unión, por lo cual destacaron la voluntad del ser humano como factor determinante para los cambios de la realidad.

La objetivación puede ser fetichización (y por tanto alienación), porque el encuentro del investigador y del actor social es siempre transformador (de ambos y de la realidad observada y analizada, porque el conocimiento se construye al fragor de la lucha), y puede obligar a desaprender lo aprendido y a reajustar la praxis (como lo advierte la cuarta Tesis sobre Feuerbach: "se critica teóricamente y se revoluciona prácticamente”). Efectivamente, la ciencia no se aboca solamente a interpretar el mundo sino también a transformarlo (Tesis XI), o en palabras de Wallerstein, la ciencia social "explica la realidad [...] para actuar en ella", es decir, es una "búsqueda a la vez intelectual y política”. (Aubry, 2007, p. 114)

El distanciamiento del socialismo real se profundiza aún más cuando las discusiones se trasladan del escenario económico al filosófico, así como cuando los filósofos profesionales descalifican la naturaleza de los filósofos clásicos y los escenarios de multiplicación de las tesis revolucionarias de los sindicatos de fábrica o escuelas de partido pasan a las universidades, de tal forma que la nueva época les otorga un creciente carisma académico.

La teoría marxista había emigrado de manera prácticamente total a las universidades, lugares de refugio y exilio al mismo tiempo de las luchas políticas del mundo exterior. En este periodo, Lukács, Lefebvre, Goldmann, Korsch, Marcuse, Delia Volpe, Adorno, Colletti y Althusser ocuparon todos cargos universitarios con rango de profesores. (Anderson, 1979, p. 65)

En concordancia, los estudios críticos de los pensadores occidentales no se centraron en la crítica al pensamiento de Hegel y de sus herederos, como lo hizo Marx. El objetivo teórico de sus pensamientos se centró en la crítica del propio Marx, de la cual destacaron los análisis que hizo a los principios epistemológicos con los que el marxismo interpreta y transforma el mundo, así como a los cánones de la investigación social. Algunos resultados se registraron en obras como Marxismo y filosofía, de Korsch, ¿Qué es marxismo ortodoxo?, de Lukács, Razón y revolución, de Marcuse, El problema del método y La crítica de la razón dialéctica, de Sartre, entre otros. 
En contraste, la elaboración académica de los teóricos occidentales se caracterizó por el uso de un lenguaje elaborado y de complejidad verbal, carente de un lenguaje llano y sencillo, lo cual produjo complicaciones en la comprensión de las tesis y el distanciamiento con la práctica popular: "En este sentido, el lenguaje del marxismo occidental estuvo sujeto a una censura histórica más amplia: el abismo abierto durante casi cincuenta años entre el pensamiento socialista y el suelo de la revolución popular" (Anderson, 1979, p. 71). Tal vez Gramsci es la excepción a los intelectuales de la vertiente occidental que no incurrió en esta práctica academicista, pues a diferencia de los filósofos profesionales, su obra se desarrolla desde la praxis como dirigente revolucionario de clase obrera (Anderson, 1979).

La consecuencia de tal estancamiento fue el meditado silencio del marxismo occidental en los campos más importantes para las tradiciones clásicas del materialismo histórico [...] Gramsci es la única excepción a esta regla y este es el sello de grandeza que lo distingue de todas las otras figuras de esta tradición [...]. Después de Gramsci, ningún otro marxista de Europa occidental lograría realizaciones similares. (Anderson, 1979, p. 59)

Desde esta estructura del pensamiento — sin demeritar o desconocer los aportes de los demás pensadores del marxismo occidental— emerge la filosofía de la praxis y los conceptos de bloque histórico y hegemonía de Antonio Gramsci, que sin negar su esencia marxista, le critica y reasigna una nueva interpretación que ubica al ser humano como gestor de las revoluciones en occidente.

En este sentido, Gramsci enfrenta cualquier posibilidad de trascendentalismo definiendo el marxismo como inmanentismo absoluto, que comprende el historicismo absoluto, la mundanización y terrestridad absoluta y el humanismo absoluto. Desde este planteamiento, el pensador italiano acusa de ingenuidad las tesis que le asignan a la historia una realidad trascendente, reafirma su postura con la negación de un más allá y reconoce lo humano como supremo y terminal (Sáenz, 1987, p. 8).

Las tesis de los propulsores del Marx joven se encontraron un poco más tarde con el marxismo italiano de Antonio Gramsci, que concibió la filosofía de la praxis como método de interpretación del marxismo desde la inmanencia absoluta en negación de cualquier interpretación trascendentalista de la vida y la revolución cultural como instrumento que combata desde la hegemonía popular "los tres factores históricos genéticos de la alienación humana: la propiedad privada, la división del trabajo y la producción mercantil" para la construcción de un hombre nuevo. (Silva, 1982, p. 21)

La construcción teórica de Gramsci parte de la concepción del bloque histórico que diferencia la estructura y la superestructura (instituciones formadoras del 
sentido común), y desde allí se distanció de la fundamentación dogmática, la cual consideraba que era necesario transformar las fuerzas productivas y sus relaciones de producción para que triunfara la revolución. Desde esta perspectiva, la estructura pasa a un segundo nivel y la superestructura se ubica como un escenario en el que se conciben las ideas, las teorías y las formas de conciencia social en un primer plano, con lo cual se aplica el principio de cambiar lo que hay en las cabezas antes que cortar las cabezas. De esta manera se espera que "al conquistar el poder político, el proletariado suprime la propiedad privada burguesa que impide el desarrollo de las fuerzas productivas" (Rosental \& Iudin, 1946). En contraste, para el pensador sardo, la prioridad del proceso revolucionario debe ser cambiar la superestructura como bastión del trabajo alienante que se ha dado por parte del bloque dominante.

Gramsci corrige [...] la férrea trabazón que el marxismo (sobre todo el marxismo escolástico) establece entre la infraestructura o estructura (las fuerzas y relaciones de producción: de producción de las condiciones materiales de la existencia) y la superestructura: religión, Estado, derecho, familia, etc. En esa corrección, Gramsci es drástico. La revolución, para él, debe pasar por la conquista de lo que pertenece al ámbito de la superestructura (la sociedad civil). La conquista de la sociedad política (poder del Estado) vendrá por sí sola. (Del Noce, 1977, p. 17)

En concordancia, emulando las dos formas del Centauro de Maquiavelo de la que emana la trilogía de los sistemas estatales territorio, autoridad y consenso (Anderson, 1979), Gramsci considera al Estado como la articulación de la sociedad civil y la sociedad política. La primera está constituida por el grupo de instituciones como la familia, la iglesia, los partidos, los sindicatos, las instituciones de educación, los grupos empresariales y los medios de comunicación, los cuales son aparatos de reproducción de hegemonía que construyen la realidad y los valores. La segunda, la sociedad política, es el grupo del que emana la autoridad y la coerción.

De este modo, Gramsci elabora la tesis de la hegemonía, como resultado del equilibrio que debe haber entre el consenso respecto a las tesis del gobernante que se construye con la identificación, la confianza y el reconocimiento del pueblo, y la actividad coercitiva que vela por el cumplimiento de los parámetros que la sociedad civil ha construido desde su propia cosmovisión, valores, principios y tradiciones. De ahí que en el proceso revolucionario el enfrentamiento político e ideológico que conducen los intelectuales orgánicos en el interior de la sociedad civil busca mutar el sentido común y, por esta vía, despojar al sistema imperante del consenso del pueblo, lo cual genera un estado de crisis orgánica que lo acorrala y solo le deja el recurso de la coerción, lo cual deslegitima su actuar. 
El concepto de hegemonía en Gramsci se refiere a la estrategia desplegada por un determinado grupo social para generar la aceptación de sus propias posiciones ideológicas entre los otros grupos sociales por medio de la persuasión y el consenso. [...] El ámbito en el que se desarrolla la lucha entre las clases para establecer su hegemonía es la sociedad civil. Aquí es fundamental la labor de los intelectuales, que articulan los intereses y coordinan las iniciativas de la clase a la que representan en el proceso de instaurar su hegemonía sobre las otras clases sociales. Lo que Gramsci pretende con esta noción es elaborar una teoría de la hegemonía del proletariado en el contexto de la crisis orgánica del Estado burgués. (Ruiz, 2016, p. 2)

Con este propósito, la teoría gramsciana plantea como estrategia la revolución cultural (superestructura), la cual tiene el objetivo de conquistar la hegemonía mediante un proceso civilizatorio de deconstrucción y construcción que elimine los mecanismos de alienación con los que el bloque dominante modela el sentido común. En esta dirección, Gramsci comprende la religión como un aparato de hegemonía que incide en la conformación del sentido común a partir de la concepción del mundo y la vida de las masas populares, de manera que no plantea "la eliminación de la religión o las iglesias, sino superarlas crítica y progresivamente hasta sustituirlas con una concepción superior de la vida y del mundo y con una organización social y política diferente" (Pastor, 2017, p. 8).

La obra de Gramsci estuvo constantemente centrada en temas superestructurales, [...] abordó la cuestión de la autonomía y la eficacia de las superestructuras culturales como un problema político, que debía ser examinado teóricamente como tal de modo explícito, en su relación con el mantenimiento o la subversión del orden social [...]. Así, la temática cultural e ideológica ha predominado uniformemente en el marxismo occidental del principio al fin. (Anderson, 1979, p. 97)

Para occidente, esta estrategia propone superar la guerra de maniobra de la revolución bolchevique, en la cual los levantamientos masivos de la población permitirían en poco tiempo asaltar el poder. Como alternativa, Gramsci plantea la guerra de posiciones, que considera una estrategia sutil, indetectable, pero profundamente destructiva, la cual se desarrolla sin tiempo definido, desgasta y deconstruye el poder del bloque dominante en la disputa por la hegemonía.

La guerra de maniobra se define como el ataque directo y rápido que destruye al enemigo, como el asalto al Estado, tal cual se dio en la Revolución de Octubre. La guerra de posición, en cambio, tiene el carácter de una guerra de desgaste, de cercamiento, y naturalmente requiere tiempos distintos y una gran hegemonía. [...] propone ganar el apoyo de la inmensa mayoría de las masas trabajadoras, destruyendo el consenso social en torno a ese Estado y generando uno nuevo, una nueva organización de la vida. (Leal, 2019, p. 58) 
En la guerra de posiciones, la estrategia se conduce en dos tiempos: inicialmente se desarrolla la etapa de desmontaje del bloque dominante utilizando tácticas de desprestigio y ridiculización, que buscan desgastar progresivamente su imagen. A partir de allí, en la segunda etapa, se profundizan las contradicciones y los errores que tenga el sistema, de manera que se acentúen el descontento y el aislamiento del gobierno en el ámbito nacional y en los espacios internacionales.

Tratar de que la clase dirigente pierda el consenso [...], para ello hay que tratar de despojarla de su prestigio espiritual, desmitificando los elementos de su cosmovisión mediante una crítica continua y corrosiva. Esta crítica debe sembrar la duda, el escepticismo y el desprestigio moral en relación de quienes dirigen. Debe destruir sus creencias y sus instituciones y debe corromper su moralidad. (Sáenz, 1987 , p. 23)

Por este camino, se verificaron los errores que condujeron a la crisis del socialismo real y se expusieron las tesis del marxismo humanista, que erigió la filosofía de la praxis como la vertiente que no solo fundamenta la teoría revolucionaria, sino que además guía la estrategia de revolución cultural para lograr la emancipación. En este escenario, el marxismo se reedita en América Latina y supera el modelo de partido único — que, a manera de vanguardia, imponía verticalmente el pensamiento único - por un discurso más amplio que evita el discurso dogmático y recoge los diversos inconformismos e indignaciones que surgen de la inequidad del desarrollo global.

El marxismo ha arreglado cuentas de manera amplia con su pasado economicista, determinista, teleológico, maniqueo y eurocéntrico (Munck, 2000). Desde esa perspectiva crítica de renovación marxista posestructural podemos ahora examinar el gran dinamismo, así como las crecientes inequidades del desarrollo global contemporáneo. (Munck, 2010, p. 52)

El neomarxismo, considerado "por lo común aquel que se distanció del 'marxismo oficial' establecido en los países del llamado 'socialismo real'” (Biagini \& Roig, 2008, p. 370), superó el reduccionismo que genera la lucha de clases y su visión economicista, que la circunscribe a la confrontación de pobres contra ricos, campesinos contra terratenientes y obreros contra los empresarios. Así, acogió los intereses de los grupos ambientalistas, de género, religiosos, étnicos, jóvenes, campesinos y desposeídos, de tal manera que transformó el sujeto histórico —que pretéritamente recaía en la clase obrera - en un sujeto colectivo representado en los movimientos sociales. 
Por todas estas razones, el nuevo sujeto histórico abarca al conjunto de los grupos sociales sometidos, tanto los realmente sometidos (representados por los llamados "antiguos movimientos sociales") como los formalmente sometidos ("nuevos movimientos sociales"). El nuevo sujeto histórico por construir ha de ser popular y plural, es decir, constituido por una multiplicidad de actores. (Houtart, 2006, p. 437)

Sin embargo, para resignificar el sujeto histórico en los movimientos sociales también es necesario identificar los desafíos de la globalización y establecer los cambios que se deben impulsar e institucionalizar para cumplir el objetivo emancipador. Consciente de que el bloque dominante trata de cooptar los movimientos sociales, el neomarxismo se enfoca en la sociedad civil, en la sociedad civil de abajo, con lo cual recupera "el concepto de Antonio Gramsci que la considera como el lugar de las luchas sociales [...]. [Así] En el plan global, la sociedad civil de arriba se reúne en Davos y la sociedad civil de abajo en Porto Alegre" (Houtart, 2006, p. 439).

En este sentido, después de constatar la caída del bloque soviético e identificar la crisis estructural del capitalismo neoliberal — sobre los que recaían respectivamente las tesis de emancipación (por la lucha de clases) y felicidad (mediante el incremento de la producción) de los pueblos_-, los intelectuales críticos ponen en discusión la vigencia del modelo racionalista de la Ilustración: "El proyecto de construir un mundo con arreglo a los principios de la razón universal no se ha alcanzado ya que tan solo hicieron parte de las intenciones de poder de quien las sustenta" (Smith, 1993, p. 70). De ahí que el poder en mano de naciones imperialistas y clases dominantes reivindica que "su forma de ver las cosas implica una visión universal y racional” (Smith, 1993, p. 70). Es decir, quien ostenta la razón universal ejerce la alienación sobre los sectores subalternos de la sociedad y los Estados periféricos.

Se trata aquí de un uso distinto de la asimetría estratégica que más que intimidar, que es tarea principalmente del poderío bélico o económico, se propone legitimar un modo de vida colocando a la tecnología como medio, soporte y justificación de la enajenación de sentidos. La internalización de las imágenes de realidad producidas por el poder, en vez y en contra de las imágenes construidas colectivamente, genera seres de conciencia enajenada, seres vaciados de impulso sujético. (Ceceña, 2006, p. 37)

En consecuencia, quienes rechazan los planteamientos del racionamiento y se inscriben en la posmodernidad abogan por la política de la identidad contra el monopolio de la razón y las formas generales de opresión (moral...), buscan que la multiplicidad de movimientos sociales sea escuchada y que de ellos mismos surjan las propias cosmovisiones, organizaciones políticas y estructuras comunicacionales 
(Smith, 1993). De acuerdo con Gramsci, los movimientos sociales, como esencia de la sociedad civil, elaboran su autonomía, su sentido común, en rechazo de la coerción y opresión que impone el bloque imperante.

El lugar decisivo para prevenir y/o disuadir cualquier intento por modificar las reglas del juego o por construir diques al dominio capitalista y apagar la rebeldía, la disidencia o la insurgencia es el cultural, donde radican la memoria histórica, las cosmovisiones, las epistemes y las utopías. (Ceceña, 2006, p. 36)

En concordancia, los intelectuales críticos exponen que para producir el cambio social radical se requiere forjar la unidad desde la autonomía e independencia de cada movimiento, de tal manera que las múltiples alianzas de los oprimidos se construyan lejos de la tesis reduccionista de la lucha de clases y respetando la especificidad identitaria de cada movimiento. Para los posmodernistas, el papel que desempeña la clase obrera en el marxismo ortodoxo no constituye per se un agente del cambio central que deba recibir privilegios, sino que forma parte del universo de movimientos de transformación dentro de una dirección colegiada.

El verdadero objetivo de construir el socialismo tiene que ser el de conferir una auténtica representación al proletariado en su conjunto, lo que resulta imposible si no florece el pluralismo político, ideológico y cultural para las masas... Sin esta clase de pluralismo los trabajadores no serán capaces de detentar realmente el poder. (Smith, 1993)

El cúmulo de transformaciones políticas, económicas y culturales que produce la postura rupturista de la posmodernidad aproxima a la humanidad a un cambio de época y no a una época de cambio. Para Zygmunt Bauman, la caída del muro de Berlín en 1989 cerró la época moderna, inaugurada en 1789 con la Revolución Francesa, y dio paso a las realidades y al espíritu posmodernos (Bauman, 1991). La tesis se complementa con las palabras del expresidente de Ecuador Rafael Correa, cuando anunció que "el país empezaba a salir de la larga noche del neoliberalismo y el continente ya no estaba en una época de cambio, sino en un cambio de época, la larga y triste noche neoliberal está siendo derrotada y un nuevo amanecer se avizora en cada rincón de esta América mestiza” (Sader, 2017, p. 1).

Desde el levantamiento Zapatista en México de 1994, la elección presidencial de Hugo Chávez en Venezuela en 1998 y la histórica "Segunda Cumbre de los Pueblos" realizada en Quebec, 2001, un cambio profundo ha sacudido "el patio trasero" del imperio. Bolivia y Ecuador, lo mismo que Venezuela [...] han defendido un nuevo Socialismo para el siglo XXI. (Cockcroft, 2011, p. 2) 
El cambio de época también se caracteriza por el análisis que diversas disciplinas hacen sobre las múltiples circunstancias a las que el modelo de desarrollo capitalista neoliberal ha conducido a la humanidad. Específicamente, sostienen que la modernidad ha sido acaparada por las fuerzas imperiales mediante su posición de poder dominante, por lo cual desde el pensamiento único ha sido selectiva en la construcción de la realidad pretendiendo homogeneizarla, hacerla parte del todo al desconocer a manera de colonialismo la multiplicidad de cosmovisiones. Es decir, la globalización, en cuanto utopía del libre mercado autorregulado para imponer los valores universales, caminó en esta dirección ejerciendo la función selectiva y discriminatoria de la realidad. Y, como señala Smith (1993), "para Marx, los valores dominantes son los valores de la clase dominante” (Smith, 1993).

Para el sociólogo y filósofo del derecho Boaventura de Sousa Santos, la homogeneización cultural que emana de los países centrales hacia la periferia engulle con voracidad las diversas expresiones culturales diferenciales, destruye sus cosmovisiones, arrasa con las identidades de los pueblos, con la estructura social, sus valores y la vida. Por ello, en palabras del sociólogo portugués, se hace necesario rebautizar la realidad con un ánimo emancipatorio que construya distintos horizontes civilizatorios.

Es evidente que tenemos que construir una contrahegemonía, pero primeramente partamos de que la hegemonía es básicamente sentido común en sentido gramsciano. Es un sentido común que ratifica al presente tal y como existe, con sus injusticias, dominaciones y con sus opresiones, no podemos desistir de crear un nuevo sentido común que deje de justificar este presente y que desnaturalice la opresión, la explotación, la discriminación, la violencia y las masacres. (De Sousa, 2013, p. 41)

Para la filósofa Isabel Rauber, las acciones de barbarie y opresión del modelo capitalista animan la construcción de alternativas para enfrentar la hegemonía de dominación y sometimiento, así como los mecanismos de producción y reproducción del modelo imperialista. Consciente de las múltiples identidades y verdades que surgen en el pluralismo político, ideológico y cultural que produce la posmodernidad, la autora señala que el "nudo articulador de los procesos de cambio social [es] la construcción de una nueva civilización”, de un nuevo mundo. Rauber agrega que este nuevo mundo emerge de las luchas populares hacia la construcción desde abajo de un nuevo poder revolucionario, el poder popular, "que le permita al campo popular convertirse en un bloque o fuerza popular hegemónica" (Rauber, 2016, pp. 30-31). 
La construcción de un nuevo mundo, de una nueva civilización late en los procesos de luchas populares, particularmente cuando estos se anudan y orientan hacia la construcción de un nuevo poder, propio, revolucionario [...] nuevos modos de interrelaciones sociales, colectivas, grupales, comunitarias. En ellas van construyendo y desarrollando una hegemonía propia, anclada en la participación de todos y todas, de modo que el actor popular colectivo (auto)constituido, despliegue y proyecte su conciencia política y su independencia de pensamiento en acciones políticas, económicas y culturales encaminadas a conquistar su liberación y la de la sociedad toda, alimentando — sobre esa base — la naciente civilización simultáneamente con la profundización del poder popular. (Rauber, 2016, p. 30)

Sin distanciarse mucho de los postulados gramscianos de revolución cultural, los teóricos de la posmodernidad consideran que el proceso civilizatorio se soporta en la construcción de una nueva hegemonía. Esta renovación conlleva, a manera de subversión, una etapa de deconstrucción de la hegemonía dominante que emancipa —en la lucha y la resistencia — el sentido común y la cotidianidad, de tal manera que libres al fin de la alienación y provenientes de otras cosmovisiones, se crean y maduran colectivamente en el reconocimiento y reconstrucción de socialidades (Cесейa, 2006).

Emancipación parecía, en pleno auge del neoliberalismo, un concepto en desuso que había quedado relegado al rincón de las nostalgias. No obstante, hoy reaparece cobrando nuevos sentidos y abriendo nuevas y viejas esperanzas, y, correlativamente, llamando a una sublevación del pensamiento [...]. No hay subversión posible si no abarca el pensamiento, si no inventa nuevos nombres y nuevas metodologías, si no transforma el sentido cósmico y el sentido común que, como es evidente, se construyen en la interacción colectiva, haciendo y rehaciendo socialidad. (Ceceńa, 2006, pp. 13-14)

El proceso de deconstrucción de la hegemonía del bloque dominante constata lo que Gramsci advertía sobre la demolición del Estado, es decir, que la lucha en el seno de la sociedad civil se da en doble sentido: por un lado, se deconstruye la hegemonía de la dominación, cimentada en la jerarquización, el verticalismo y la exclusión, mientras, por el otro, se construye la hegemonía popular, que se caracteriza por la lucha contra el capitalismo y la creación "de una nueva civilización humana, liberadora, justa, solidaria, diversa y ecológicamente sustentable" (Rauber, 2016, p. 36).

En este sentido, la crisis del paradigma occidental de la modernidad exige que el marxismo radicalice su crítica a la modernidad desde una visión amplia y renovada para afrontar temas que Marx ni Engels advirtieron, como la evidente crisis ecológica, que constituye una amenaza real a la humanidad y a todas las formas 
existentes de vida sobre el planeta. Por esta razón, es fundamental impulsar una férrea oposición al modelo de civilización industrial que arrastra a la humanidad al suicidio, como "condición para pensar una nueva realidad y articular a partir de ella un nuevo paradigma” (Jameson, 1993, p. 93).

Las costumbres colectivas de antaño son reproducidas no tanto por tradición y cultura, sino por estrategia de sobrevivencia o, en todo caso, por ambas. No se trata de una acción planeada ni de nostalgias del pasado, sino de urgencias de un presente difícil que solo así ofrece salidas a la degradación o extinción. (Ceceña, 2006, p. 38)

En consecuencia, desde la perspectiva marxista, el socialismo intenta construir un nuevo modelo de civilización en el cual se empeña por revalorar y restablecer diversos elementos del pasado engendrados por los pueblos ancestrales, que aportan desde su cosmovisión a lo humano, lo cultural, lo social-ético y al relacionamiento del hombre con la naturaleza, otrora destruidos por la modernidad burguesa (Lowy, 1993).

En este quehacer, el proyecto socialista no solo produce un nuevo paradigma que se distancia del socialismo real reeditando la utopía, en el sentido que "sin utopía revolucionaria no habrá práctica revolucionaria”, sino que además realiza un proceso civilizatorio emancipador que rescata la sabiduría milenaria y los intereses grupales para superar todas las lógicas civilizatorias de dominación de la modernidad y resolver los problemas de toda la civilización, y no de una parte de ella.

Los nuevos sujetos colectivos incorporan los intereses grupales sobre los individuales en el que uniendo las capacidades articulan las indignidades individuales que de manera grupal y organizada se moviliza en pro del logro de los objetivos propuestos. De la acción colectiva surgen los movimientos sociales como actor protagónico que enfrentando la alienación del capitalismo enarbolando las tesis de la libertad, la autonomía y la identidad dan paso a un nuevo paradigma. (Cortés, 2019, p. 153).

\section{Conclusiones}

Para el marxismo internacional y, en especial, para los intelectuales latinoamericanos, la tesis de Fukuyama sobre el fin de la historia fue un motivante para reeditar el marxismo a partir de la caracterización del modelo dominante y la autocrítica del estalinismo.

Los Manuscritos económico-filosóficos de 1844 o Manuscritos de París se erigieron como referentes para la nueva interpretación del marxismo en las circunstancias de dominio del capitalismo neoliberal. Así, las tesis de la alienación y la enajenación 
les permitió afirmar que las condiciones impuestas por la globalización pretenden homogeneizar la humanidad en una sociedad de consumo estandarizada, individualista y egoísta, una sociedad que no respeta las fronteras del bien común por sus ansias de acumulación y que pone en peligro la existencia misma de la humanidad con sus agresiones a la naturaleza. Precisamente, este hecho le confiere al modelo de desarrollo capitalista el calificativo de modelo inhumano.

Asimismo, el fracaso del modelo estalinista estimuló el estudio de nuevas vertientes del marxismo, que acudieron a las tesis del marxismo humanista del Marx joven para analizar las circunstancias deshumanizantes que caracterizan al modelo capitalista neoliberal. Por esta vía, en la vertiente del marxismo occidental hallaron las propuestas de la filosofía de la praxis y de la revolución cultural del italiano Antonio Gramsci, que les sirvió como referente de estudio para enfrentar el modelo hegemónico.

Desde esta perspectiva, los errores del socialismo real —el dogmatismo, el verticalismo, el vanguardismo, el estrategismo y el autoritarismo - se superan con las nuevas tesis: la vanguardia es colectiva, el sujeto de la revolución no recae sobre el sector obrero, sino que se amplía al sujeto colectivo, representado en los movimientos sociales. Así, el verticalismo se supera con la organización horizontalizada colegiada; el dogmatismo, con el discurso pluritemático y, finalmente, el estrategismo, con la construcción de la estrategia en la praxis.

El marxismo posmoderno elabora su marco de referencia con base en las tesis del legado de Antonio Gramsci, particularmente en los conceptos de superestructura, guerra de posiciones, bloque histórico, hegemonía, sociedad civil, sociedad política, intelectuales orgánicos, sentido común, realidades y valores.

Por su parte, el pensamiento crítico radical argumenta que el capitalismo neoliberal pasa por una crisis generalizada, una crisis financiera, de la hegemonía estadounidense, de la economía mundial de sobreacumulación, sobreproducción y consumo, alimentaria, y civilizatoria, que exige al neomarxismo elaborar un nuevo paradigma que resuelva los problemas de la humanidad. La construcción de este nuevo paradigma emancipatorio debe partir de la crítica radical al paradigma dominante para construir desde allí el poder popular que impulse el camino a la hegemonía de liberación, en el cual es fundamental interrelacionar los saberes y las prácticas ancestrales con las nuevas indignaciones y movimientos sociales para fortalecer la cultura popular.

El análisis de la realidad que hace el pensamiento crítico radical diagnostica que los paradigmas capitalista y comunista de la modernidad están agotados. En este sentido, las circunstancias de dominio del capitalismo neoliberal que conducen a la humanidad a su extinción motiva la elaboración de un nuevo paradigma que supere la visión economicista para considerar a toda la humanidad. 
Desde una mirada más amplia, el pensamiento crítico expone que actualmente la crítica no se centra en las relaciones de dependencia de la periferia hacia el centro que establece el sistema mundo, en el sistema capitalista o en las políticas de los gobiernos neoliberales, sino en el sistema civilizatorio de la modernidad eurocéntrica.

Finalmente, el agotamiento del paradigma de la modernidad, sin que se observen posibilidades de renovación, produce un cambio de época y no una época de cambios. En esta renovación, los postulados de la posmodernidad se abren paso como paradigma alternativo para construir, desde la revolución cultural, un proceso civilizatorio que reformule la realidad del universo y los valores que conduzcan a la humanidad a la coexistencia armónica con la naturaleza.

\section{Conflicto de intereses}

Los autores declaran que no existe ningún potencial conflicto de interés relacionado con este capítulo.

\section{Financiación}

Los autores no declaran fuente de financiamiento para la realización de este capítulo.

\section{Referencias}

Amadeo, J. (2006). Mapeando el marxismo. En A. Borón, J. Amadeo, \& S. González (Eds.), La teoría marxista hoy: problemas y perspectivas. CLACSO.

Anderson, P. (1979). Consideraciones sobre el marxismo occidental. Siglo XXI.

Aubry, A. (2010). Los intelectuales y el poder. Otra ciencia social. Revista Contrahistorias, 8, 11-116.

Baeza, M. (2006). Globalización y homogeneización cultural. Sociedad Hoy, 10, 9-24. https://www. redalyc.org/pdf/902/90201002.pdf

Bartra, A. (2013). Crisis civilizatoria. En R. Ornelas, Crisis civilizatoria y superación del capitalismo. UNAM.

Baudrillard, J. (2009). La sociedad del consumo. Sus mitos, sus estructuras. Siglo XXI.

Bauman, Z. (1991). Modernity and ambivalence. Polity.

Bermudo, J. (2010). Los manuscritos de París. http://www.jmbermudo.es/marx/manuscritos-paris.html

Biagini, H., \& Roig, A. (2008). Diccionario del pensamiento alternativo. Biblos.

Borón, A. (1999). Pensamiento único y resignación política. Revista Nueva Sociedad, 169, 139-151.

Borón, A. (2006). Teoría política marxista o teoría marxista de la política. En A. Borón, J. Amadeo, \& S. González (Eds.), La teoría marxista hoy: problemas y perspectivas. CLACSO. 
Borón, A., \& Massholder, A. (2014). Pensamiento estratégico estadounidense. Revista de Estudios Estratégicos, 2, 40-52. http://biblioteca.clacso.edu.ar/Cuba/cipi/20180327101826/REE2.pdf

Brzezinski, Z. (1997). El gran tablero mundial. La supremacia estadounidense y sus imperativos geoestratégicos. Paidós.

Casas, A. (2007). El socialismo que no fue. Revista Herramienta, 36. https://herramienta.com.ar/articulo.php?id=536

Castellanos, C., \& Suárez, M. (2009). Estado, democracia, ciudadanía, acción política y DESC. En Derechos económicos, sociales y culturales (pp. 339-412). Kimpres.

Ceceña, A. (2006). Sujetizando el objeto de estudio, o de la subversión epistemológica como emancipación. En Los desafíos de las emancipaciones en un contexto militarizado. CLACSO. http:// biblioteca.clacso.edu.ar/clacso/gt/20101019085312/2Cecea.pdf

Cockcroft, J. (2011). Cambio de época. Cambio de Época, Órgano de los Movimientos Sociales y Ciudadanos de Nuestra América, 1.

Coraggio, J. (2014). Otra política, otra economía, otras izquierdas. En J. L. Coraggio, \& J.-L. Laville (Orgs.), Reinventar la izquierda en el siglo XXI. Hacia un diálogo Norte-Sur (pp. 35-84). Universidad Nacional General Sarmiento, CLACSO, IAEN. http://biblioteca.clacso.edu.ar/ clacso/se/20140918020441/ReinventarLaIzquierda.pdf

Cortés, D. (2019). Neo marxismo y revolución cultural. Utopía y Praxis Latinoamericana, 24(3), 149-166.

De Sousa, B. (2013). Pensadores y poderes. La construcción de horizontes civilizatorios. En O. D. Soto Badillo, \& M. A. Sánchez Díaz de Rivera (Coords.), El poder hoy [Conferencias Magistrales de la Cátedra Alain Touraine] (pp. 41-69). México: Universidad de Puebla.

De Sousa, B. (2014). ¿¿Reinventar las izquierdas? En J. L. Coraggio, \& J.-L. Laville (Orgs.), Reinventar la izquierda en el siglo XXI. Hacia un diálogo Norte-Sur (pp. 143-164). Universidad Nacional General Sarmiento, CLACSO, IAEN. http://biblioteca.clacso.edu.ar/clacso/se/20140918020441/ ReinventarLaIzquierda.pdf

Del Noce, A. (1977). Italia y el eurocomunismo: una estrategia para Occidente. Magisterio.

Escobar, A. (2014). De la crítica al desarrollismo al pensamiento sobre otra economía: pluriverso y pensamiento relacional. En J. L. Coraggio, \& J.-L. Laville (Orgs.), Reinventar la izquierda en el siglo XXI. Hacia un diálogo Norte-Sur (pp. 191-206). Universidad Nacional General Sarmiento, CLACSO, IAEN http://biblioteca.clacso.edu.ar/clacso/se/20140918020441/ReinventarLaIzquierda.pdf

Fair, H. (2008a). El sistema global neoliberal. Polis, 7(21), 229-263. https://scielo.conicyt.cl/pdf/ polis/v7n21/art12.pdf

Fair, H. (2008b). La globalización neoliberal: transformaciones y efectos de un discurso hegemónico. KAIROS. Revista de Temas Sociales. http://www.revistakairos.org/la-globalizacion-neoliberal-transformaciones-y-efectos-de-un-discurso-hegemonico/

Fair, H. (2010). Hacia una epistemología del neoliberalismo. Revista Pensar. Epistemología y Ciencias Sociales, 5, 131-150. https://revistapensar.org/index.php/pensar/article/view/52/47

Galafassi, G. (2011). Teorías diversas en el estudio de los movimientos sociales. Una aproximación a partir del análisis de sus categorías fundamentales. Cultura y Representaciones Sociales, 6(11), 7-32.

Gray, J. (septiembre 6, 2002). El fin de la historia toca a su fin. La Nación. https://www.lanacion.com. ar/opinion/el-fin-de-la-historia-toca-a-su-fin-nid 428816 
Gudynas, E. (2013). Transiciones hacia un nuevo regionalismo autónomo. En Grupo Permanente de Trabajo sobre Alternativas al Desarrollo (Eds.), Alternativas al capitalismo / colonialismo del siglo XXI (pp. 129-160). Abya-Yala. https://www.rosalux.org.ec/pdfs/Alternativas-al-capitalismo.pdf

Guerrero, M., López, L., \& Herrera, N. (2017, marzo 31). ¿Para qué sirvió la revolución rusa? https:// kaosenlared.net/para-que-sirvio-la-revolucion-rusa/

Harnecker, M. (1999). Haciendo posible lo imposible. La izquierda en el umbral del siglo XXI. Siglo XXI. http://biblioteca.clacso.edu.ar/Cuba/mepla/20111107115815/posible.pdf

Harnecker, M., \& Rauber, I. (1991). Hacia el siglo XXI. La izquierda se renueva. CEESAL. http://biblioo teca.clacso.edu.ar/clacso/otros/20111108110655/siglo.pdf

Herreño, A. (2009). Derecho al desarrollo. En Derechos económicos, sociales y culturales (pp. 339-412). Kimpres.

Hinkelammert, F. (2001). El nibilismo al desnudo. Los tiempos de la globalización. Ed. Lom.

Hinkelammert, F. (2005). La universidad frente a la globalización. Polis, 11. https://polis.ulagos.cl/ index.php/polis/article/view/377

Houtart, F. (2006). Los movimientos sociales y la construcción de un nuevo sujeto histórico. Ponencia presentada en el marco del V Encuentro Hemisférico contra el ALCA y el Libre Comercio, La Habana, Cuba.

Jameson, F. (1993). Marxismo y posmodernismo. Vientos del Sur, 11, 86-99. https://cdn.vientosur. info/VScompletos/vs_0011.pdf

Jeifets, V., \& Jeifets, L. (2016). La Comintern y la formación de militantes comunistas latinoamericanos. Izquierdas, 31, 130-161. https://scielo.conicyt.cl/pdf/izquierdas/n31/0718-5049-izquierdas-31-00130.pdf

Katz, C. (2010). Las tres dimensiones de la crisis. Revista Mundo Siglo XXI, 22, 5-34.

Katz, C. (2014). Miradas pos-desarrollistas. https://rebelion.org/miradas-pos-desarrollistas/

Kruschev, N. (1956). Informe secreto al XX Congreso del PCUS. https://www.marxists.org/espanol/ khrushchev/1956/febrero25.htm

Lang, M. (2013). ¿Por qué buscar alternativas? A manera de Introducción. En Grupo Permanente de Trabajo sobre Alternativas al Desarrollo (Eds.), Alternativas al capitalismo / colonialismo del siglo $X X I$ (pp. 7-24). Abya-Yala.

Leal, A. (2019). Gramsci. Cambio 21. https://www.academia.edu/29681255/GRAMSCI

Lince, W. (2017). A 100 años de la Revolución Bolchevique y 50 del Capital de Karl Marx: dialéctica y síntesis de su conmemoración. Kavilando, 9(2), 333-334. https://www.kavilando.org/revista/ index.php/kavilando/article/view/222/188

Lincopi. (2016). El marxismo ortodoxo de Lukacs. Marxismo y revolución. https://docplayer. es/55397122-El-marxismo-ortodoxo-de-lukacs.html

López, J. (2014, enero 20). El fracaso del socialismo real. Crónica Popular. https://www.cronicapopular.es/2014/01/el-fracaso-del-socialismo-real/

Lowy, M. (1993). Para afrontar los problemas actuales, el marxismo necesita radicalizar la crítica de la modernidad. Vientos del Sur, 11, 99-104. https://cdn.vientosur.info/VScompletos/vs_0011.pdf

Mancilla, H. (1989). Aspectos comparativos del socialismo en el tercer mundo: teoría y realidad de la modernización. Revista de Estudios Políticos [Nueva época], 63, 219-232. 
Marcuse, H. 1970. Los manuscritos económico-filosóficos de Marx. Ideas y Valores, 35-37, 17-56. https://revistas.unal.edu.co/index.php/idval/article/view/29083/29358

Márquez, A. (2017). Antonio Gramsci y el nuevo orden: hacia la creación de una nueva hegemonía. Autografía.

Márquez, H. (2009). Diez rostros de la crisis civilizatoria del sistema capitalista mundial. Revista Problemas del Desarrollo, 40(159), 191-210.

Márquez, H. (2010). La gran crisis del capitalismo neoliberal. Andamios, 7(13), 57-84. scielo.org.mx/ pdf/anda/v7n13/v7n13a4.pdf

Marx, K. (1974). Manuscritos economía y filosofía. Alianza.

Monge, E. (2013). Alienación y revolución: la escritura de los Manuscritos de 1844 de Marx. Hic Rhodus. Crisis capitalista, Polémica y Controversias, 4, 12-26. http://biblioteca.clacso.edu.ar/ Argentina/iigg-uba/20140625051548/336-1255-1-PB.pdf

Munck, R. (2010). La teoría crítica del desarrollo: resultados y prospectiva. Migración y desarrollo, 14, 35-57. http://www.scielo.org.mx/pdf/myd/v8n14/v8n14a3.pdf

Munck, R. (2017). Desarrollo y democracia en América Latina: resultados y perspectivas. Estudios Críticos del Desarrollo, 7(12), 55-85. http://www.iisec.ucb.edu.bo/assets_iisec/publicacion/ ECDvol_VIInum_121.pdf

Palacios, F. (1998). Neoliberalismo, hegemonía y nuevo orden. Estrategia y resultante social en Latinoamérica. Revista de Estudios Políticos [Nueva época], 99, 59-101. https://recyt.fecyt.es/ index.php/RevEsPol/article/view/45208

Pastor, J. (2017, abril 27). Apuntes sobre el pensamiento político de A. Gramsci [información en página web]. Viento Sur. https://vientosur.info/spip.php?article12514

Patińo, A. (2004). Neoliberalismo, desigualdad y exclusión. Tendencias, Revista de la Facultad de Ciencias Económicas y Administrativas, 5(1-2), 131-156. https://revistas.udenar.edu.co/index. $\mathrm{php} / \mathrm{rtend} /$ article/view/812/1017

Pozzi, P., \& Pérez, C. (2011). Por el camino del Che. Las guerrillas latinoamericanas 1959-1990. Imago Mundi.

Rauber, I. (2016). Hegemonía, poder popular y sentido común. El Ágora USB. Revista de Ciencias Sociales, 16(1), 29-62. https://revistas.usb.edu.co/index.php/Agora/article/view/2164/1892

Rinesi, E. (2014). Presentación por la Universidad Nacional General Sarmiento UNGS. En J. L. Coraggio \& J.-L. Laville (Orgs.), Reinventar la izquierda en el siglo XXI. Hacia un diálogo Norte-Sur (pp. 13-16). Universidad Nacional General Sarmiento, CLACSO, IAEN. http:// biblioteca.clacso.edu.ar/clacso/se/20140918020441/ReinventarLalzquierda.pdf

Rosental, M., \& Iudin, P. (1946). Diccionario filosófico marxista. Pueblos Unidos.

Ruiz, C. (2016). Estado, sociedad civil y hegemonía en el pensamiento político de Antonio Gramsci. Revista de Filosofía y Teoría Política, 47. http://sedici.unlp.edu.ar/bitstream/ handle/10915/56554/Documento_completo.pdf-PDFA.pdf?sequence=1 \&isAllowed=y

Sader, E. (2017, mayo 25). Época de cambio y cambio de época. América Latina en Movimiento. https://www.alainet.org/es/articulo/185710

Sáenz, A. (1987, agosto). Gramsci y la revolución cultural [Conferencias pronunciadas el 12 y 13 de agosto de 1987 en la sede de la Corporación de Abogados Católicos, Libertad 850, Capital 
Federal. Argentina]. http://reportecatolicolaico.com/2016/03/antonio-gramsci-y-la-revolucion-cultural/

Samour, H. (2007). Posmodernidad y filosofía de la liberación. Revista de Filosofía A Parte Rei, 54, 1-17. http://serbal.pntic.mec.es/ - cmunoz11/samour54.pdf

Silva, L. (1982). Teoría del socialismo humanista. Humanismo clásico y humanismo marxista. Monte Avilés.

Silva, R. (2017, julio 14). Los peligrosos valores del neoliberalismo [información en página web]. Rebelión. https://rebelion.org/los-peligrosos-valores-del-neoliberalismo/

Smith, A. (1776). La riqueza de las naciones. Epublibre.

Smith, T. (1993). Teoría política del posmodernismo. Vientos del Sur, 11, 69-76. https://cdn.vientosur.info/VScompletos/vs_0011.pdf

Sotelo, A. (2005). América Latina: de crisis y paradigmas. La teoría de la dependencia en el siglo XXI. Plaza y Valdés.

Stróganov, A. (2015, febrero 5). ¿Por qué se fundó la Universidad de la Amistad de los Pueblos? Rusia Beyond. https://es.rbth.com/cultura/2015/02/05/por_que_se_fundo_la_universidad_de_la_ amistad_de_los_pueblos_47027

Tejedor, C. (2014). Las falacias de la ideología neoliberal. Oximora Revista Internacional de Ética y Politica, 5, 41-62. https://revistes.ub.edu/index.php/oximora/article/view/10781/14480

Valenzuela, J. (2006). Socialismo y marxismo: dos ¡cadáveres? (Regímenes burocrático-autoritarios y marxismo vulgar). Andamios, 3(5), 129-162. http://www.scielo.org.mx/pdf/anda/v3n5/ v3n5a8.pdf

Vega, R. (abril 18, 2009). Crisis civilizatoria. https://prensarural.org/spip/spip.php?article2197

Vergara, J. (2003). La utopía neoliberal y sus críticos. Polis Revista Latinoamericana, 6, 1-26. https:// journals.openedition.org/polis/6738 